\title{
Preparation of highly exfoliated epoxy/clay nanocomposites by clay grafted with
}

\section{liquid crystalline epoxy}

Fei Chen, Yuehua Cong, Baoyan Zhang*, Zeqing Wang, Bing Yao

1. A pre-weighed amount of organophilic clay, the certain quantity of concentrated sulfuric acid and $\mathrm{CuSO}_{4} .5 \mathrm{H}_{2} \mathrm{O} / \mathrm{Na}_{2} \mathrm{SO}_{4}$ are added to distilling flask. Organic ammonium of organophilic clay is decomposed and $\mathrm{NH}_{4} \mathrm{HSO}_{4}$ can generate in the reaction when the mixed system are heated to boil, and then the excess concentrated sulfuric acid is neutralized using concentrated sodium hydroxide solution. Since then, $0.1 \mathrm{~mol} / \mathrm{L} \mathrm{HCl}$ is used to absorb $\mathrm{NH}_{3}$ when the above system is treated by steam distillation. The residual $\mathrm{HCl}$ in the process is measured by $0.05 \mathrm{~mol} / \mathrm{L} \mathrm{NaOH}$ and phenolphthalein used as an indicator, therefore, the ion exchange capacity can be calculated according to $\mathrm{NaOH}$ consumption in the titration process.

$$
\begin{gathered}
\mathrm{CEC}=\frac{\mathrm{C}_{1} \mathrm{~V}_{1}-\mathrm{C}_{2} \mathrm{~V}_{2}}{\mathrm{M}} \times 100 \\
\mathrm{X}=\frac{\mathrm{CEC}}{\mathrm{CEC}^{\prime}} \times 100 \%
\end{gathered}
$$

CEC: Cation-exchange capacity $(\mathrm{mmol} / 100 \mathrm{~g})$;

C1: Hydrochloric acid solution concentration (mol/L);

V1: Dosage of hydrochloric acid solution (ml);

C2: Sodium hydroxide solution concentration (mol/L);

V2: Dosage of sodium hydroxidesolution (ml);

m: The quality of organophilic clay;

CEC': Pristine clay cation-exchange capacity (mmol/100g);

$\mathrm{X}$ : Ion exchange ratio (\%)

2. synthesis routes of 4-(Oxiran-2-ylmethoxy)-benzoic acid cholesterol ester (SOAC)

4-Hydroxybenzaldehyde (6.10 g, $50.0 \mathrm{mmol})$ was dissolved in $2 \mathrm{M} \mathrm{NaOH}$ (30 ml). Epichlorohydrin $(4.68 \mathrm{~g}, 50.0 \mathrm{mmol})$ was added dropwise to the solution stirred at 
$0{ }^{\circ} \mathrm{C}$. Reaction mixture was stirred overnight at room temperature. The solution was extracted with dichloromethane $(3 \times 25 \mathrm{ml})$ and the combined organic phases washed with $1 \mathrm{M} \mathrm{HCl}(3 \times 40 \mathrm{ml})$, water $(40 \mathrm{ml})$, and brine $(25 \mathrm{ml})$. The organic phase was dried with $\mathrm{Na}_{2} \mathrm{SO}_{4}$, and the solvent removed under reduced pressure. The crude product was purified with flash column chromatography on silica (MF: petrolether/ethyl acetate $=2: 1$ ). Yield $79 \%$.

4-(Oxiran-2-ylmethoxy)benzaldehyde $(5.80 \mathrm{~g}, 32.6 \mathrm{mmol})$ was pulverized in a 100-ml flask and 30\% hydrogen peroxide $(50 \mathrm{ml})$ was added. The reaction mixturewas stirred vigorously for $30 \mathrm{~min}$ at room temperature. Dichloromethane $(100 \mathrm{ml})$ was added and the phases were separated. The organic phase was washed with brine, dried over $\mathrm{Na}_{2} \mathrm{SO}_{4}$, and the solvent removed under reduced pressure. White solid. Yield $86 \%$.

A mixture of 4-(Oxiran-2-ylmethoxy)benzaldehyde $(0.01 \mathrm{~mol})$ and cholesterol (0.01 mol) was dissolved in $200 \mathrm{ml}$ dry $\mathrm{N}, \mathrm{N}$-dimethylformamide(DMF) in a round-bottomed flask. The DCC solution $(0.01 \mathrm{~mol})$ and a catalytic amount of 4-dimethylaminopyridine (DMAP) in $50 \mathrm{ml}$ of DMF was added dropwise to the above system under continuous stirring. The reaction system was stirred for $24 \mathrm{~h}$ at room temperature, and the by-product (N,N-dicyclohexylurea) was then filtered off. After removal of the solvent, the product was precipitated by the addition of water to the residue and the crude product was obtained by filtration and recrystallised from ethyl acetate: ethanol (2:1). Yield: 78\%.

${ }^{1} \mathrm{H}-\mathrm{NMR}\left(600 \mathrm{MHz}, \mathrm{CDCl}_{3}, \delta\right): 7.97-7.95$ (d,J=9 Hz, 2H, Ar-H), 6.92 (d, J=9 Hz, 2H, Ar-H), $4.30(\mathrm{~m}, 1 \mathrm{H}), 3.99(\mathrm{~m}, 1 \mathrm{H}), 3.36(\mathrm{~s}, 1 \mathrm{H}), 3.26(\mathrm{~s}, 1 \mathrm{H}), 3.11(\mathrm{~s}, 1 \mathrm{H})$, $2.91(\mathrm{~m}, 1 \mathrm{H}), 2.76(\mathrm{~m}, 1 \mathrm{H}), 2.30-0.61(\mathrm{~m}, 44 \mathrm{H}$, cholesteryl-H).

3. Synthesis routes of 4-(4-Oxiranyl-methoxyl)-benzoic acid cholesterol ester (DOAC)

Potassium hydroxide $(8.0 \mathrm{~g}, 0.14 \mathrm{~mol})$ and potassium iodide $(0.35 \mathrm{~g}, 0.002 \mathrm{~mol})$ was added to a solution of p-hydroxybenzoic acid $(8.3 \mathrm{~g}, 0.06 \mathrm{~mol})$ in $200 \mathrm{~mL}$ of ethanol. After the reaction mixture was stirred at room temperature for $1 \mathrm{~h}$, allyl bromide ( $9 \mathrm{~g}, 0.08 \mathrm{~mol}$ ) was added dropwise to the mixture. The resulting mixture 
was heated under reflux overnight. After this had cooled to room temperature, $1 \mathrm{~mol} / \mathrm{L} \mathrm{HCl}$ solution was added to neutralize the reaction mixture. The white precipitate was filtered and recrystallized from ethanol twice to give white piece crystals in $88 \%$ yield and with melting point $(\mathrm{Tm})$ at $165{ }^{\circ} \mathrm{C}$.

$8.9 \mathrm{~g}$ of 4-(2-allyloxy)benzoic acid, $15 \mathrm{~mL}$ of thionyl chloride were added to a round-bottomed flask equipped with an absorption instrument of hydrogen chloride. The mixture was stirred at room temperature for $4 \mathrm{~h}$, and then heated to $60{ }^{\circ} \mathrm{C}$ for $6 \mathrm{~h}$, the excess thionyl chloride was distilled under reduced pressure to give the corresponding acid chloride. Yield: $97 \%$.

$7.84 \mathrm{~g}(0.04 \mathrm{~mol})$ of 4-(2-allyloxy)benzoicacyl chloride was added dropwise to a cold solution of $15.44 \mathrm{~g}(0.04 \mathrm{~mol})$ of cholesterol in $40 \mathrm{ml}$ of chloroform and 2 $\mathrm{ml}$ of pyridine. The reaction mixture was heated to reflux for $16 \mathrm{~h}$. The mixture was cooled to room temperature, poured into $200 \mathrm{~mL}$ of methanol. The precipitated crude product was filtered and recrystallized from ethanol:toluene (2:1). The yield of $\mathrm{AC}$ is $84 \%$ with $\mathrm{Tm}$ at $116^{\circ} \mathrm{C}$.

$5.46 \mathrm{~g}$ of $\mathrm{AC}$ was dissolved in $50 \mathrm{~mL}$ of dry $\mathrm{CH}_{2} \mathrm{Cl}_{2}$ was added dropwise to a solution of metachloroperbenzoic acid (MCPBA, $4.3 \mathrm{~g}, 0.025 \mathrm{~mol}$ ) in $300 \mathrm{~mL}$ of dry $\mathrm{CH}_{2} \mathrm{Cl}_{2}$ under continuous stirring. The reaction mixture was stirred and refluxed for $48 \mathrm{~h}$. After cooling and subsequent filtration, the solvent was evaporated to dryness in rotary evaporator. The crude product obtained was washed with ethanol and then filtered three times. The yield of OAC is $80 \%$ with Tm at $129^{\circ} \mathrm{C}$.

${ }^{1} \mathrm{H}-\mathrm{NMR}\left(600 \mathrm{MHz}, \mathrm{CDCl}_{3}, \delta\right): 7.97-7.95$ (d,J=9 Hz, 2H, Ar-H), 6.92 (d, J=9 Hz, 2H, Ar-H), $4.30(\mathrm{~m}, 1 \mathrm{H}), 3.99(\mathrm{~m}, 1 \mathrm{H}), 3.36(\mathrm{~s}, 1 \mathrm{H}), 3.26(\mathrm{~s}, 1 \mathrm{H}), 3.11(\mathrm{~s}, 1 \mathrm{H})$, $2.91(\mathrm{~m}, 1 \mathrm{H}), 2.76(\mathrm{~m}, 1 \mathrm{H}), 2.30-0.61(\mathrm{~m}, 44 \mathrm{H}$, cholesteryl-H). 


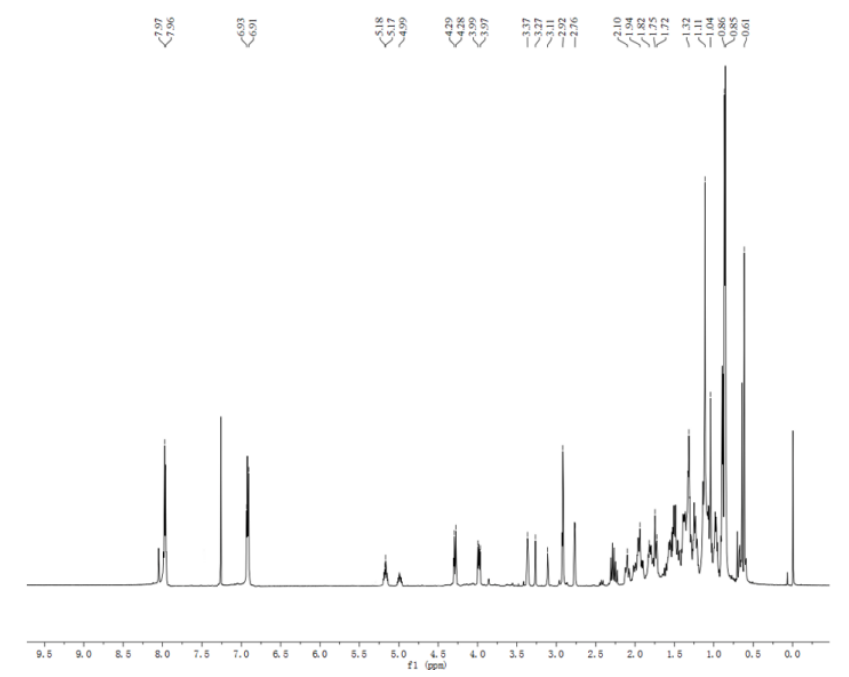

Figure $\mathrm{S} 1{ }^{1} \mathrm{H}-\mathrm{NMR}\left(\mathrm{CDCl}_{3} / \mathrm{TMS}, \mathrm{d}, \mathrm{ppm}\right)$ spectrum of SOAC.

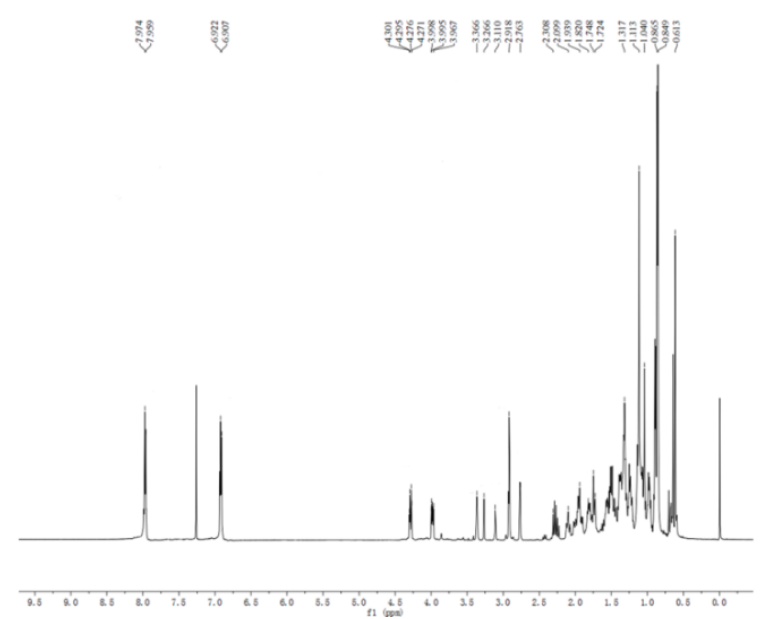

Figure $\mathrm{S} 2{ }^{1} \mathrm{H}-\mathrm{NMR}\left(\mathrm{CDCl}_{3} / \mathrm{TMS}, \mathrm{d}, \mathrm{ppm}\right)$ spectrum of DOAC.
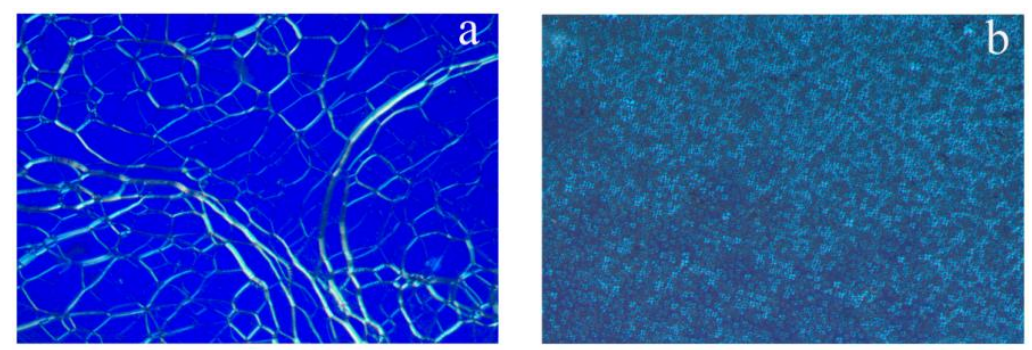

Figure S3 Polarized optical micrographs $(\times 200)$ of DOAC at heating process. (a) $140{ }^{\circ} \mathrm{C}$, (b) $200{ }^{\circ} \mathrm{C}$. 


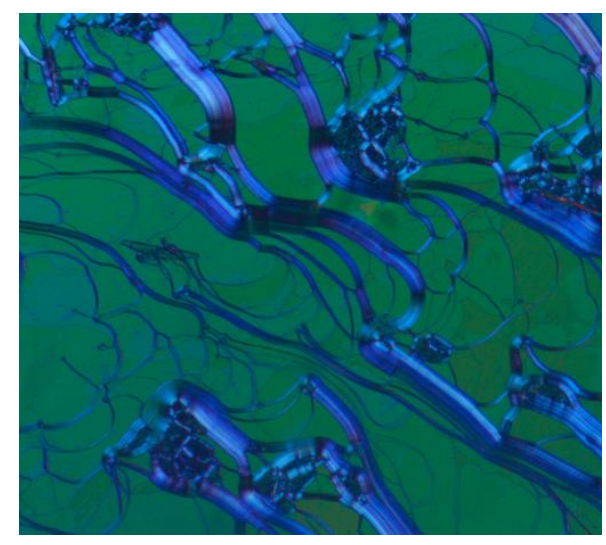

Figure S4 Polarized optical micrographs $(\times 200)$ of SOAC at $140{ }^{\circ} \mathrm{C}$ of heating process.

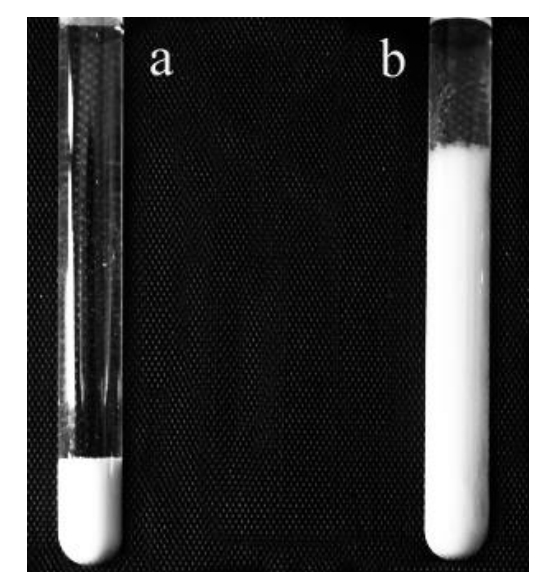

Figure S5 Dispersion state of (a) M-clay and (b) DOACM-clay in trichloromethane. 